\title{
Kernos
}

Revue internationale et pluridisciplinaire de religion grecque antique

6 | 1993

Varia

\section{À propos de la Mégalographie de Pompéi}

\section{Pierre Somville}

URL : http://journals.openedition.org/kernos/555

DOI : 10.4000/kernos.555

ISSN : 2034-7871

\section{Éditeur}

Centre international d'étude de la religion grecque antique

\section{Édition imprimée}

Date de publication : 1 janvier 1993

Pagination : 301-307

ISSN : 0776-3824

\section{Référence électronique}

Pierre Somville, «À propos de la Mégalographie de Pompéi », Kernos [En ligne], 6 | 1993, mis en ligne le 07 avril 2011, consulté le 22 avril 2019. URL : http://journals.openedition.org/kernos/555 ; DOI :

10.4000/kernos.555 
Kernos, 6 (1993), p. 301-307.

\section{À PROPOS DE LA MÉGALOGRAPHIE DE POMPÉI}

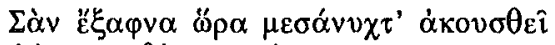

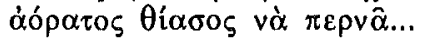

Lorsqu'à minuit soudain on entendra l'invisible thiase qui passe...

(CAVAFY)

Comment se risquer encore, après Maiuri, Matz, Boyancé, Nilsson et tant d'autres, à proposer un élément de lecture neuf pour la célèbre mégalographie de la "Villa des mystères"? Il n'y faut cependant voir nulle présomption. C'est que l'abondance et la qualité des commentaires n'épuisent pas la polysémie plastique d'un chef d'œuvre "sans légende». On peut toujours ajouter un petit cube coloré à la grande mosaïque inachevée.

Dès lors, embarquons, non sans rappeler d'entrée l'interprétation historique de G.E. Rizzo ${ }^{1}$ qui, dès 1914, voyait dans ce somptueux décor découvert cinq ans plus tôt par Aurelio Item l'illustration d'un rituel dionysiaque. Même si l'auteur y sollicite abusivement une influence orphique issue d'Italie du Sud, allant jusqu'à identifier à Korè la déesse (mutilée) qui trône sur le panneau central, rien n'est venu mettre en question son éclairante hypothèse. Le dionysisme romain, mieux connu et mieux perçu depuis les travaux de A.J. Festugière ${ }^{2}$ relatifs au récit de Tite-Live notamment, se passe désormais de l'obligatoire et omniprésente imprégnation grecque. D'ailleurs, les accointances archaïques de Liber pater et de Dionysos ${ }^{3}$, qu'elles soient analogiques ou historiques, n'imposent plus le moindre postulat réducteur. On pourrait en dire autant du pythagorisme d'un Varron, d'un Nigidius Figulus, voire d'un Ovide.

1 Dionysos mystes (contributi esegeti alle rappresentazioni di misteri orfici), Mem. dell' Accademia di Napoli, 4 (1914), p. 92-102.

2 Etudes de religion grecque et hellénistique, Paris, Vrin, 1972, spéc. p. 89 et sq.

3 Cf. l'ouvrage d'A. BRUHL, Liber pater. Critique et expansion du culte dionysiaque à Rome et dans le monde romain, Paris, 1953. 
Dans une récente synthèse, assurément hâtive, consacrée aux cultes à mystères, W. Burkert ${ }^{4}$ commettait, au moins, deux erreurs : il considérait comme allant de soi que la lecture du décor devait se faire de gauche à droite de manière univoque et ininterrompue. De plus, il parlait une fois encore de la fameuse flagellation comme d'un fait établi. Or, dans une ingénieuse contribution, G. Sauron ${ }^{5}$ proposait récemment une lecture symétrique et plurielle culminant en une scène centrale d'uunion". Il a cependant eu le tort, me semble-t-il, d'identifier la déesse à Sémélè et de vouloir ramener à la naissance du dieu tout le volet mythique de cette série d'images, sans doute moins univoque. D'autre part, R. Turcan ${ }^{6}$ a montré, à deux reprises au moins, combien était fragile le conformisme d'interprétation, presque universellement répété, de la femme fouettée. Rien n'impose en effet, que la verge brandie par la démone ailée, sorte de Nikè inversive, doive s'abattre sur le dos dénudé de l'impétrante prostrée à l'angle proche de la paroi de droite. Le geste fustigateur peut fort bien être, dans l'absolu, apotropaïque ou fécondateur, ou les deux à la fois, et ce, sans aucune référence figurative ou narrative.

Dès avant l'hypothèse de Sauron, j'ai toujours pensé à une composition symétrique et bilatérale, progressant parallèlement jusqu'au paroxysme de l'iepòs yónos. Peut-être n'aurais-je pas dû tant tarder à le dire. En tout cas les préparations, réalisations et épreuves successives semblent se développer en regard les unes des autres, n'était, créant l'asymétrie, la travée interrompant l'image sur le long côté de droite. On a ainsi quatre scènes à gauche pour deux seulement à droite, mais elles semblent membre à membre se répondre : le geste d'épouvante (à gauche) face à la nudité offerte (à droite); prolongeant la scène d'ablution, l'allaitement préparatoire (à gauche) face aux préliminaires (à droite) de la course au thyrse, habillée, et de la danse, nue, accompagnée de crotales. Il n'en va pas autrement des décors du chœur de l'église Saint François d'Arezzo: les deux scènes de visites et de défilé se regardent, comme les deux batailles au plan inférieur. Seuls

4 Les cultes à mystères dans l'antiquité, Paris, Les Belles Lettres, 1992 (Vérité des mythes), p. 87 et 94 notamment.

5 Nature et signification de la mégalographie de Pompéi, Communication à l'Académie des Inscriptions et Belles Lettres, Paris, 1984, compte rendu aux p. 151-174.

6 La déesse de la villa Item, in Hommages à Marcel Renard, III, Bruxelles, Latomus, 1969, p. 586-609; Pour en finir avec la femme fouettée, in RA (1982), p. 291-302. 
les oculi marquent le début et l'issue de cette «légende» de la Croix. Tout autre essai de lecture chronologique ou diégétique est voué à l'échec ou à l'aberration. C'est le sens des masses et de leur équilibre qui a guidé Piero della Francesca pour une composition structurale en quelque sorte. De même à la Villa Item, la "procession» rituelle ou symbolique, qui fait s'avancer le spectateur dans la nef, le conduit entre une double série d'images, évoquant sans doute davantage le rite que le mythe, vers la scène ultime représentant l'union du dieu et de la déesse, encadrée de la Nikè bottée, verge brandie, et d'une étrange catoptromancie, tandis que l'impétrante découvre, dans un van, le phallos divin.

La célébration nuptiale semble bien être l'image-clé de la mégalographie comme de l'initiation dionysiaque. C'est, tradition-nellement, l'union de Dionysos et d'Ariane qui en offre l'image mythique et symbolique. Quant au rituel, que nous connaissons mal, puisqu'il était soumis au secret, il devait comporter sans doute plus d'une allusion, également symbolique, à la célébration du mariage. $O$. Brendel et $M$. Bieber $^{7} \mathrm{y}$ ont songé, à juste titre. Mais insistons encore. Certes, la déité féminine de la scène centrale, peu identifiable à cause d'une irréparable lacune, apparaît en domina trônante, mais rien n'empêche d'y voir l' "Ari-adnè» souveraine, recevant en son giron le jeune dieu incliné vers l'arrière, à l'image même de Mars aux genoux de Vénus, dans les premiers vers du poème de Lucrèce. Le dieu, thyrse en travers et torse dénudé, chaussé d'une seule sandale ${ }^{8}$, est plus clairement identifiable, il est vrai. Cela dit, l'allusion au mariage sacré ne semble faire aucun doute, pas davantage que la velléité d'union mystique souhaitée par les fidèles, et promise à l'impétrante, moyennant une symbolique nuptiale adéquate.

À cet égard, on connaît au moins un cas très célèbre et peu douteux de mariage symbolique ou mystique s'inscrivant dans le cadre d'un rituel dionysiaque. Il s'agit des célèbres vendanges bacchiques au cours desquelles Messaline "épouse» Silius. Tacite et Juvénal ${ }^{9}$ nous en ont fait le récit, malveillant à souhait : chose fortuite ou concertée, on ne

7 In $J D A I, 81$ (1966), p. 206-206; 43 (1928), p. 291-330, respectivement.

8 C'est le pied droit qui est nu et la crépide, bien visible, est rejetée à l'avant-plan. On songe à une éventuelle extension rituelle à la formule horatienne : Nunc est bibendum, nunc pede libero / Pulsanda tellus... (Ode, I, 37, 1-2). Cf. à ce propos S. CURLETTO, La norma e il suo rovescio (coppie di opposti nel mondo relgioso antico), Gênes, 1990, p. 150 et sq.

9 TAC., Ann., XI, 26-38 (cf. spéc. 31, 2); JUV., Sat. , X, 329-345 (cf. spéc. v. 333-334). 
sait.. Ces deux écrivains, en tout cas, n'étaient pas des initiés. Le même Tacite et Suétone ${ }^{10}$ mentionnent également, avec une bienpensante répulsion, les noces homosexuelles de Néron avec Pythagoras et Doryphoros. Peut-être faut-il également disculper l'empereur, attiré dès sa relation avec la jeune Actè par les cultes orientaux. L'auteur de tant de stupres, connus et reconnus, doit bien bénéficier de l'élémentaire critique historique visant à ne pas en surcharger la noirceur ${ }^{11}$. Festugière ${ }^{12}$ nous a rappelé en son temps combien la mauvaise interprétation, notamment homosexuelle, de "prétendues" initiations dionysiaques avait amené Tite-Live à condamner ces «bacchanales" qui préludèrent au fameux sénatusconsulte de 186 av. J.-C.

Dès lors, revenons à nos images, et à deux thèmes précis que nous avons jusqu'ici négligés. À gauche, en entrant, après la domina accoudée sur l'imposte, une jeune impétrante voilée s'apprête à la "procession". Juste en face d'elle, à droite, nous assistons à la toilette nuptiale de la future épouse : un petit éros lui tend le miroir, tandis qu'elle ajuste sa coiffure. Comme le fera la Messaline de Juvénal, elle porte le flammeum, le célèbre voile jaune de la fiancée. Quelques pas plus loin, la danseuse aux crotales, comme une Ariane dévoilée, se voit le même voile jaune gonflé en corolle latérale autour du corps, comme si elle était la redite, presque aboutie, de la nymphè flanquée aussi de sa demoiselle d'honneur, prête à rencontrer le dieu. Les dominantes de jaune et de mauve (couleurs complémentaires) s'imposent d'ailleurs à plus d'une reprise sur le fond pourpre de la mégalographie à décor de grecques, bardée de noir, de vert et d'or.

Cette image de la nymphe, peu reproduite, isolée à droite en entrant, nous parait primordiale dans tous les sens du terme : c'est elle qui nous indique les tenants (rituels) et les aboutissants (symboliques) de la cérémonie d'initiation dont les diverses phases vont être perpétuées par les décorations des trois parois. Si le détail des objets et des actes nous en échappe largement, c'est qu'il en va comme des orgia ${ }^{13}$ dont on ne

10 T AC., Ann. XV, 37, 8-9; S UÉT., Néron, 29 ,1.

11 Cf. le bel article de J. Colin, Les vendanges dionysiaques et la légende de Messaline (48 ap. J.-C.), in LEC, 24 (1956), p. 25-39.

12 Op. cit., p. 89-109.

13 Nous savons désormais que ce terme désigne souvent des objets liés au rite d'initiation. Cf. à ce propos A. MotTe, V. PirenNe-Delforge, Le mot et les rites. Aperçu des significations de ópүı et de quelques dérivés, in Kernos, 5 (1992), p. 119-140, spéc. p. 138. 
pouvait parler après les avoir vus... La teneur dionysiaque et symboliquement nuptiale semble pourtant en être acquise.

Pour dernier témoignage, voici un texte, peu cité en cette occurrence. Il est extrait de l'épithalame de Catulle consacré aux noces de Thétis et de Pélée et plus exactement du long epullion central consistant en une description du voile de la mariée. Il y est question des amours d'Ariane et comme on peut s'y attendre, le point final - et culminant - de cette belle ekphrasis évoque l'arrivée de Dionysos et de son escorte féminine14 :

Harum pars tecta quatiebant cuspide thyrsos

Pars e diuolso iactabant membra iuuenco

Pars sese torsis serpentibus incingebant

Pars obscura cauis celebrabant orgia cistis

Orgia, quae frustra cupiunt audire profani

Plangebant aliae proceris tympana palmis

Aut tereti tenuis tinnitus aere ciebant...

Certaines d'entre elles agitaient des thyrses à la pointe couverte,

D'autres brandissaient les membres d'un taureau dépecé,

D'autres se ceignaient la taille de serpents lovés,

D'autres encore portaient en procession dans de vastes corbeilles,

De ces objets qu'en vain les profanes voudraient qu'on leur nomme,

Certaines, paumes levées, frappaient des tambourins

Ou faisaient retentir d'un son suraigu les cymbales de bronze...

On nous accordera que cet extrait évoque un climat bien proche de celui de nos "mystérieuses" images, dont il risque d'être, d'ailleurs, l'exact contemporain.

Université de Liège

Pierre SOMVILLE

Place du XX-Août, 32,

B - 4000 LIÈGE

14 Pièce 64, v. 256-262 (éd. G. Lafaye, C.U.F., 1958). 


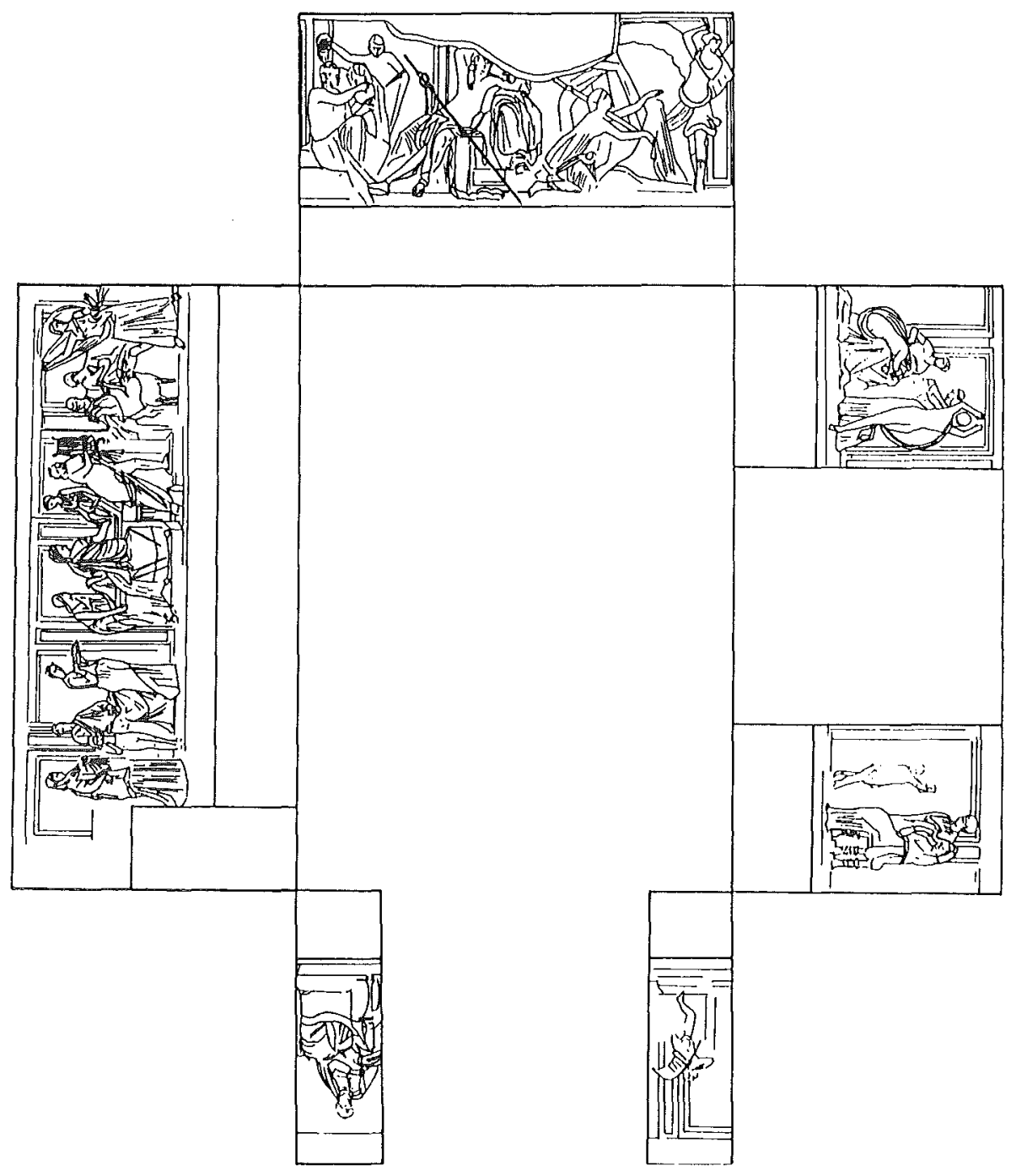

Fig. 1 : Schéma de la mégalographie, env. $7 \mathrm{~m} / 5 \mathrm{~m}$. Ier s. av. J.-C. (d'après R. Étienne) 


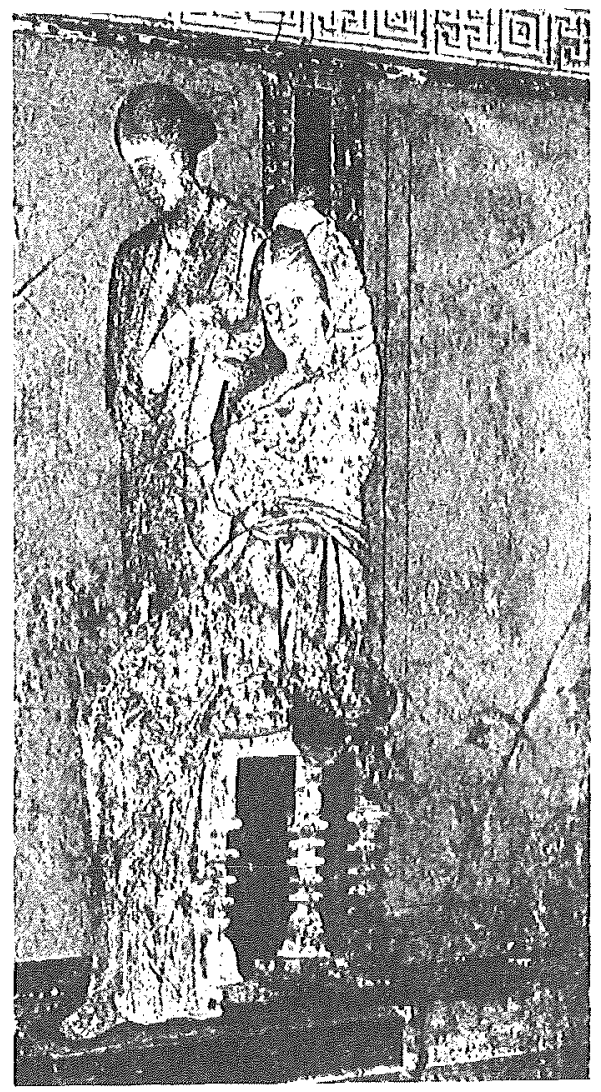

Fig. 2 : La toilette nuptiale 